\title{
Família acolhedora e reordenamento institucional: (Im)possibilidades diante do Menorismo
}

\author{
Foster family and reordering: (im) possibilities before Menorism
}

\author{
Rachel Fontes Baptista \\ Maria Helena Rodrigues Navas Zamora ${ }^{2}$
}

\begin{abstract}
RESUMO:
A família acolhedora caracteriza-se como uma política pública cujo objetivo principal está alinhado com a proteção de crianças e adolescentes em situação de violação de direitos humanos. Diante do abuso há intervenção do poder judiciário para afastar a criança da família de origem. Contudo a intenção ao final do processo é a reunificação familiar quando possível e segura. Neste contexto, objetiva-se, a partir do referencial teórico da análise institucional, problematizar a implementação da política de família acolhedora, prevista no reordenamento institucional, mas atravessada pela visão menorista acerca das famílias de origem. Discute-se determinadas práticas que atravessam os fazeres direcionados a algumas famílias, dificultando a reunificação familiar e mesmo a efetivação da política em questão. $O$ método predominantemente bibliográfico apoia a execução do artigo. Percebe-se a presença da racionalidade menorista como coadjuvante de muitas práticas dirigidas à infância na atualidade. O olhar de quem detém o poder e cujo julgamento se faz no sentido da inadequação das formas de vida e estrutura de algumas famílias, precisa ser revisto. A possibilidade de superação do menorismo parece estar ligada à capacidade de reflexão e autoanálise na direção da desconstrução de certos preconceitos acerca das famílias de origem. Aponta-se para a necessidade de apostar mais efetivamente na participação dos envolvidos, inclusive das crianças e adolescentes, além da ampliação de estudos longitudinais sobre da temática em questão.
\end{abstract}

\section{PALAVRAS-CHAVE:}

Família acolhedora; política pública; direitos humanos.

\footnotetext{
${ }^{1}$ Psicóloga, pós-doutorado (em curso), doutora em Psicologia Clínica pela Pontifícia Universidade Católica do Rio de Janeiro (PUC-Rio) em co-orientação com o Instituto de Psicologia Cognitiva, Desenvolvimento Humano e Social (IPCDHS - Universidade de Coimbra). Bolsista CAPES. Atualmente, é perita judicial (SEJUD/TJRJ); pesquisadora e professora da Universidade Estácio de Sá (UNESA) - departamento de Serviço Social; pesquisadora associada do Laboratório Interdisciplinar de Pesquisa e Intervenção Social (LIPIS-PUC-Rio). Violência, acolhimento familiar e direitos humanos são as principais referências temáticas de trabalho.

2 Mestra e Doutora em Psicologia Clínica pela PUC-Rio. Professora da graduação em Psicologia da PUC-Rio desde 2000 e da Pós-Graduação a partir de 2012. Professora convidada da National/Global Advisory Board for Faith and Justice in Community and Society, Indiana, USA, entre 2011 e 2015. Iniciou cooperação com o Instituto de Psicologia Cognitiva, Desenvolvimento Vocacional e Social, de Coimbra, em 2012. Em 2017 passa a ser pesquisadora convidada da linha de pesquisa "Acolhimento e inclusão de jovens em risco do IPCDHS/FCT, Univ. de Coimbra e consultora do Laboratório de Intervenção na Comunidade (LInC). Vice-coordenadora do Laboratório Interdisciplinar de Pesquisa e Intervenção Social (LIPIS, da PUC-Rio)
} 


\begin{abstract}
:
The foster family is characterized as a public policy whose main objective is aligned with the protection of children and adolescents in situations of human rights violations. In the face of abuse there is intervention by the judiciary to remove the child from the origin family. However, the intention at the end of the process is family reunification when possible and safe. In this context, it is aimed, from the theoretical framework of institutional analysis, to problematize the implementation of the foster family policy, foreseen in the institutional reorganization, but crossed by the minorist vision about the origin families. It discusses certain practices that cross the actions directed to some families, making difficult the family reunification and even the effectiveness of the policy in question. The predominantly bibliographic method supports the execution of the article. The presence of the minority rationality is seen as an adjunct to many practices directed at children today. The gaze of those who hold power and whose judgment is made in the sense of the inadequacy of the forms of life and structure of some family's needs to be reviewed. The possibility of overcoming minorism seems to be linked to the capacity for reflection and self-analysis towards the deconstruction of certain prejudices about the origin families. It is pointed out that there is a need to bet more effectively on the participation of those involved, including children and adolescents, as well as the extension of longitudinal studies on the subject in question.
\end{abstract}

\title{
KEYWORDS:
}

Foster family, public policy, human rights.

A Wanderlino Nogueira Neto, in memoriam.

\section{INTRODUÇÃO}

A Família Acolhedora é uma política pública prevista na Lei 8069, de 1990, conhecida como Estatuto da Criança e do Adolescente, após sua revisão (BRASIL, 2009). Está inserida no Sistema de Garantia de Direitos Humanos de Crianças e Adolescentes (SGD ${ }^{3}$ ) brasileiro (CONANDA, 2006). Seu principal objetivo é garantir a proteção integral onde há violações de direitos deste público. Ao longo da resolução da situação problemática que ensejou o afastamento dos filhos de suas famílias de origem, estes ficam em outras famílias, selecionadas para recebê-los provisoriamente em seu espaço privado. Esta medida protetiva prima pela manutenção dos vínculos familiares e comunitários, sempre que possível.

\footnotetext{
${ }^{3}$ Ele é um conjunto de ações que atravessam os entes federais, estaduais e municipais. Sua função é articular e integrar todas as instâncias protetivas na perspectiva de garantir direitos humanos para crianças adolescentes.
} 
A proteção integral à infância afirmou-se após o mencionado Estatuto, apesar da tradição de um estado assistencialista (LEMOS, 2008) e moralista (CANTALICE, 2011), em que as políticas públicas se encontram dificuldades para sua real efetivação. Assim, na tentativa de materializar o direito adquirido à proteção social previsto na Lei Orgânica de Assistência Social (BRASIL, 1993) e colocado em prática pela Política Nacional de Assistência Social (MDS, 2004), no âmbito da alta complexidade, encontram-se os Serviços de Famílias Acolhedoras (MDS, 2004; CNAS, 2009; MDS, 2015, BRASIL, 1990). Contudo, o grande hiato entre leis e práticas de efetivação dos direitos adquiridos ainda emperra o avanço de certas políticas públicas protetivas.

Neste contexto, cumpre assinalar a reprodução de posturas e práticas dirigidas às famílias de origem desses meninos(as) cuja lógica do controle, vigilância e regulação (FOUCAULT, 1987; CASTRO, 2015, 2016) tem normalizado muitas práticas potencialmente violadoras de direitos (CORREIA, ZAMORA \& BICALHO, 2018).

Na tentativa de superar a distância entre as determinações legais e a prática devida vêm sendo criadas iniciativas que pretendem assegurar direitos conquistados. Nesta direção, o movimento de reordenamento (CNAS, 2013) das ações e instituições propõe a redefinição de posturas e práticas assistencialistas. O reordenamento intenciona reorganizar os serviços, ou seja, repensar modelos cujas tecnologias de poder ajudaram a ler a história da infância. Ele deveria nortear a implementação e manutenção da medida de acolhimento, propondo um olhar diverso para antigas lógicas pautadas principalmente na institucionalização, desqualificação e criminalização da família pobre (NASCIMENTO, CUNHA \& VICENTE, 2007). No entanto, a mera mudança de nome e lugar - de orfanatos e depois abrigos para famílias acolhedoras não modifica a lógica subjacente.

Muitas ações direcionadas às famílias têm reproduzido lógicas aqui chamadas de "menoristas", em que os comportamentos de certas famílias ainda têm sido adjetivados como disfuncionais e desestruturados, recaindo sobre elas a necessidade de tutela. O discurso instituído reproduzido a respeito da família pobre como incapaz de cuidar de seus filhos faz parte da argumentação fundante do Código de Menores (BRASIL, 1927) e de sua reformulação (BRASIL, 1979), naturalizando-se na atualidade (CAMURI et al, 2012). Nesta direção, a reflexão aqui proposta recai sobre a crítica à antiga postura assistencialista, pautada por uma 
lógica segregacionista, na qual as famílias das classes populares eram alvo de tutela do Estado (LEMOS, 2008, 2011).

A partir do referencial da Análise Institucional (RODRIGUES, 2000, 2004, 2005; BAREMBLITT, 2002; ALTOÉ, 2004), problematiza-se a continuidade de práticas "menoristas". Para a proteção à criança, em seu sentido mais amplo, devem ser constituídas práticas capazes de movimentar as engrenagens da proteção para o apoio às famílias de origem, reafirmando seu lugar de potência, mesmo diante de adversidades vividas em um contexto desigual.

Neste trabalho, será feita uma revisão bibliográfica, procurando trazer alguns impasses e experiências no tema. $\mathrm{O}$ artigo inicia expondo o conceito de família acolhedora como política pública, contemplada por diferentes normativas. Situa o movimento de reordenamento enquanto um pacto de aprimoramento da proteção integral, surgido a partir da necessidade de se efetivar ações protetivas. Culmina na problematização do conceito de "menorismo", fundamentando argumentações a respeito da continuidade de práticas que culpabilizam, condenam e afastam as famílias pobres de suas crianças.

\section{Família acolhedora: política pública em um contexto de pobreza}

A Família Acolhedora (BAPTISTA, 2006; SILVA, 2012; ROSSETTI-FERREIRA et al, 2012; BAPTISTA \& ZAMORA, 2016) está baseada em diferentes normativas (MDS, 2015, BRASIL, 1990), inscrita na categoria máxima de proteção e indicada como prioridade antes de se pensar na institucionalização. Caracteriza-se como "uma modalidade de atendimento que visa oferecer proteção integral às crianças e aos adolescentes até que seja possível a reintegração familiar ou, na sua total impossibilidade, encaminhamento para adoção" (CONANDA/CNAS, 2009, p.48, grifo das autoras).

O Serviço de Família Acolhedora (SFA) pode ser definido como iniciativa de proteção e cuidados direcionados a algumas crianças em situação de violência doméstica (GONÇALVES, 2003; HABIGZANG \& KOLLER, 2012) e/ou vulnerabilidade social. Estas precisam ser afastadas, temporariamente, respeitando-se os critérios estabelecidos. Este 
processo de separação parte da identificação de alguma circunstância em que a violação de direitos está em vias de ocorrer ou já ocorreu. Por este motivo há necessidade de intervenção junto ao local onde se encontra a criança.

A indicação é que, de início, se procure apoio na família extensa que, presumivelmente, já possui laços afetivos com a(s) mesma(s). Avós, tios, primos, irmãos adultos, padrinhos próximos podem ser considerados. Esgotadas todas as possibilidades na extensão familiar, entende-se que o direcionamento a um núcleo socioafetivo já constituído, disposto a acolher e proteger a criança ou o adolescente, pode ser mais benéfico do que uma instituição.

As famílias acolhedoras precisam ser previamente selecionadas e treinadas para disponibilizar seu tempo e afeto para compor uma parceria de cuidados juntamente com o poder judiciário. Famílias voluntárias colocam-se integralmente disponíveis para o amparo necessário, apesar de não contarem com remuneração, férias ou finais de semana para descanso (BAPTISTA \& ZAMORA, 2016). Podem receber subsídio financeiro e/ou auxílio material para suprir as necessidades dos acolhidos, mas não são reconhecidas e remuneradas como profissionais tal qual algumas iniciativas internacionais (DELGADO, 2010a, 2010b; DELGADO, CARVALHO \& PINTO, 2014; LÓPEZ et al, 2014; DELGADO et al, 2015).

No contexto brasileiro de extrema desigualdade social e pobreza, atravessada pelo modelo de economia neoliberal, muitas crianças têm sido "privadas de cuidados parentais ou estão em risco de perdê-los" ${ }^{4}$ (LUNA, 2010, p.18). O SFA vem redesenhando e adaptando suas práticas, que são melhores desenvolvidas em algumas regiões onde o SGD é mais efetivo. Entretanto, a lentidão de sua implementação (ASSIS \& FARIAS, 2013; MCA, 2016) preocupa aqueles comprometidos com a permanência de práticas de institucionalização.

As razões para o afastamento da família de origem são diversas, mas há uma categoria importante, geralmente considerada como impulsionadora da separação da criança de sua família: a negligência, dentre as demais violências domésticas. Constantemente associada a situações de pobreza e referida em 54,9\% dos casos de separação para o acolhimento (ASSIS \& FARIAS, 2013), este dado tem sido justificativo para muitas práticas indevidas.

\footnotetext{
${ }^{4}$ No original em espanhol, o termo é "Sin el cuidado parental o en riesgo de perderlo".
} 
São identificadas como negligentes aquelas pessoas cujo dever de proteção e cuidado encontra-se fora dos padrões de normalização que tem regulado a vida dos indivíduos. Estes sujeitos deveriam dispor de condições físicas, psíquicas e materiais para cuidar de seus filhos ou, em sua impossibilidade, ter a opção de buscar outra alternativa. No entanto, a pobreza perpassa a vida de muitas dessas famílias, negando-lhes a oportunidade de escolha quando submetidas a situações mais difíceis. É impossível afastar os processos que apontam a negligência de pais e familiares da expansão atual da judicialização da vida. A condição social de pobreza pode ser um facilitador para o afastamento das crianças de suas famílias (MIRANDA \& ZAMORA, 2009; NASCIMENTO, 2012).

O acolhimento familiar tem sido visto como uma solução temporária e provisória cujo objetivo principal é fazer valer a proteção integral. Contudo, muitas crianças não têm possibilidade de retorno à família nem tampouco perfil para adoção. Além disso, ao reconhecer a proteção como necessária, é preciso também repensar as formas de entendimento desta ação.

A proteção de uma criança está para além da retirada da família e encaminhamento a um serviço, seja ele qual for. Protegê-la é também acolher sua família para que se possa pensar na reintegração como meta segura (OLIVEIRA, 2007; DARAHEM, SILVA \& COSTA, 2009; SILVA, 2012; IANELLI, ASSIS \& PINTO, 2015). Para isso, cabe um novo olhar menos fundado em verdades absolutas baseadas em expertises diversas, cujas tecnologias de poder reforçam as práticas herdadas de exclusão. As forças tutelares arbitrárias (LEMOS, 2011) dirigidas a determinadas famílias são obstáculos para a possibilidade de se pensar as singularidades das mesmas, dentro de um contexto macropolítico de violações de direitos.

Neste sentido, o movimento de reordenamento deve buscar um melhor entendimento das novas possibilidades para lidar com as antigas questões sociais.

\section{O necessário reordenamento institucional}

Numerosos estudos científicos, inclusive da Psicanálise e da Psicologia do Desenvolvimento (BRONFENBRENNER, 1996; BOWLBY, 1989, 1998; WINNICOTT, 2000; KOLLER, 2011; PAPALIA, OLDS \& FELDMAN, 2013), apontaram a inadequação das 
instituições como lugares próprios para o crescimento saudável. Também foi importante a notícia de abusos e distorções do funcionamento das instituições totais (GOFFMAN, 2008), do tipo orfanato ou reformatório, incluindo tráfico de crianças, abuso e exploração sexual, maus tratos e tortura, sem maiores possibilidades de controle social ao longo da vigência dos dois Códigos de Menores.

Nesta direção de realinhamento das práticas, a construção e estruturação de diferentes serviços de acolhimento para crianças, adolescentes e jovens até 21 anos teve sua reformulação na época da gênese do Estatuto. No entanto, muitas vezes, eram serviços fora dos padrões permitidos e com defasagens nas demandas profissionais e estruturais. Faltavam-lhes espaços adequados às necessidades dos(as) meninos(as), capacitação técnica das equipes e prioridade política, além de outras demandas para que se cumprissem as determinações de tal dispositivo legal.

Em 2014, segundo o Cadastro Nacional de Crianças e Adolescente Acolhidos (CNCA), havia cerca de 730 crianças em acolhimento familiar e 45,7 mil em instituições. A lógica da institucionalização parece persistir em um ideário de proteção integral paradoxal pelo qual não raro a família é culpabilizada pelas dificuldades com suas crianças.

A respeito dos dados sobre o acolhimento familiar, de acordo com o Censo Suas de 2014, 315 municípios possuíam esse serviço. Nesse mesmo levantamento, constatou-se que 1.770 crianças ou adolescentes estavam inseridos nesta modalidade protetiva. Hoje, esse número vem crescendo, mas a cultura do acolhimento em famílias ainda está longe do ideal.

Tais dados, se comparados, revelam um grande contingente de crianças e adolescentes ainda vivenciando a lógica da institucionalização como uma alternativa real e, muitas vezes, única para suas vidas, mesmo em uma época em que o Estatuto já foi revisado. Para além dessas infâncias estão suas famílias pobres olhadas pelo viés de uma racionalidade da biomedicina (LEMOS \& VASCO, 2012), em que as estratégias de regulação estão dadas a partir da classificação de seus comportamentos.

No caminhar de mudanças de doutrinas, em 2013, foi realizado um pacto, firmado pelo Conselho Nacional de Assistência Social (MDS, 2013), para aprimorar o SUAS e colocar em prática a proteção integral prevista no Estatuto. O novo movimento, chamado de reordenamento 
institucional, está em plena expansão no momento atual. Trata-se de afirmar novas formas de lidar com antigos problemas não resolvidos ao longo da história com a mera institucionalização (ARANTES, 2016).

Assim, o reordenamento surge como uma nova força instituinte. Direciona novas práticas e enfatiza a relevância da desconstrução de certos paradigmas por meio da mudança de mentalidade, em direção a novas dimensões teóricas, éticas e metodológicas de trabalho com a infância (SILVA \& LEHFELD, 2014).

Reordenar é reorganizar, adequar, recompor, trabalhar de forma matriciada entre diversos atores do SGD para integralidade das ações. Remete a novas formas, novos pensamentos, ações conjuntas, partilhadas, enfim, a implementação de uma Rede de Atendimento. Visa investir em capacitação de recursos humanos, trabalhar em sistema de cofinanciamento e privilegiar outras ações em rede, priorizando a perspectiva do planejamento e monitoramento dos trabalhos. Ademais, esse novo movimento deseja modificar situações de vulnerabilidade por meio de atendimento e acompanhamento. Preconizam-se públicos menores, investimento em acessibilidade e adequação da infraestrutura.

A partir da mudança de paradigma pretende-se colocar em prática novos processos de gestão participativa com foco na origem da problemática das famílias, ampliando sua autonomia. Trata-se de uma tentativa de superação da assistência tradicional cujo modelo repressivo baseava-se na doutrina da situação irregular, reprodutora da desigualdade. A pretensão é de que se inaugure um novo olhar para a assistência. Neste contexto, a FA é uma possibilidade de convivência mais individualizada e humanizada, apesar de suas possíveis falhas. Essa proposta, ainda pouco implementada nos mais de cinco mil municípios brasileiros, vem na contramão de uma cultura de abusiva internação.

Para melhor entender o não cumprimento da prática de acolhimento faz-se necessário compreender a visão menorista acerca das famílias pobres e o quanto ela ainda se faz presente. 


\section{As famílias pobres e o menorismo}

A partir da segunda metade do século XIX, com o fim da escravidão e grande expansão demográfica, a preocupação dos governantes sobre o que fazer com esse excedente populacional aumentou. Visando à reformulação do Estado, crianças e famílias das classes populares, por meio de políticas discriminatórias (BULCÃO, 2002), tornaram-se alvo principal da assistência, submetidas ao saber-poder (FOUCAULT, 1987; LEMOS \& VASCO, 2012) dos médicos higienistas. O poder médico considerava muitas práticas populares de cuidado com os filhos como inadequadas, justificando a intervenção a partir de estratégias de controle baseadas nas certezas científicas (COSTA, 1979; FALEIROS, 1995; RIBEIRO, 2003; RODRIGUES, 2010).

A lógica de segregação, instituída e hegemônica, perpetuou-se no discurso de defesa da sociedade, em que práticas de institucionalização se reproduziram em um momento no qual a vida passou a ser objeto de poder e controle. Para Goffman (2008), a instituição total se caracterizava por um local de permanência longa onde viviam indivíduos, apartados socialmente, submetidos a normas específicas de dominação. A construção desse tipo de instituição era concretizada em internatos, colégios, preventórios, reformatórios, orfanatos e outras, cujo discurso justificava a necessidade de ressocialização e treinamento para o trabalho, sendo dirigida principalmente aos indígenas, negros, seus descendentes e/ou famílias mais pobres (RIZZINI \& RIZZINI, 2004; RIZZINI \& PILLOTI, 2009).

O exercício de dominação dos corpos, em uma relação de docilidade-utilidade (FOUCAULT, 1987), atravessou as novas formas de ocupação das cidades e desenvolvimento da sociedade disciplinar. A família passou a ser vigiada pelo Estado e, mais adiante, passou a ser idealmente a tutora dos filhos da nação: suas crianças.

Sendo assim, as penalidades decorrentes da falta de cuidados passaram a ter um alvo, o núcleo familiar. Especialmente o cuidador principal, geralmente caracterizado pela mãe, ficava submetido a mecanismos de vigilância por parte de diversos aparelhos sociais. No entanto, tal estratégia de controle estendeu-se das elites às classes populares-de maneiras diferentes. As crianças e famílias pobres não "ordenadas", insubmissas, eram olhadas como potencialmente perigosas, já que estariam fora da lógica capitalista de produção e trabalho, inclusive infantil. Ao caminharem pelas ruas, meninos e meninas, sem escola nem trabalho, os “menores", eram 
vistos como vagabundos e pequenos criminosos, suspeitos e, assim, recolhidos por representar potencial ameaça à sociedade (RAGO, 1985).

As famílias das classes populares, ao não se adequarem ao novo modelo higienista ou ao se recusarem a "conservar" adequadamente seus filhos (DONZELOT, 1986), passaram a ser responsabilizadas por sua pobreza e por qualquer situação vista como problemática com sua prole. Por serem mais expostas aos mecanismos de controle do Estado, eram desqualificadas e punidas.

O entendimento acerca do "menor" perpetuava-se principalmente entre aqueles que estariam em situação irregular. Inúmeros núcleos familiares foram considerados desestruturados, moralmente duvidosos (CAMURI et al, 2012) e incapazes de cuidar de seus membros (NASCIMENTO, CUNHA \& VICENTE, 2007; NASCIMENTO, LACLAZ \& ALVARENGA FILHO, 2010). Dispositivos de criminalização e patologização também incidiram sobre os pobres, colocando-os no lugar de desviantes (DONZELOT, 1986).

Em um cenário de desigualdades, o "menorismo", derivativo do adjetivo "menor", caracterizou-se como uma lógica capaz de produzir subjetivamente determinada forma de ver, discursar e agir sobre certas crianças e famílias, amplamente disseminada no século XX e reproduzida na atualidade.

Tal mentalidade supunha existirem dois tipos de crianças: as filhas de famílias (ou seja, núcleos familiares estáveis, formais, legalmente constituídos e sem maiores problemas de sobrevivência) e as "menores", que estariam em "situação irregular", fora dos moldes instituídos. Pobreza, perigo e abandono as qualificavam (ZAMORA \& PEREIRA, 2013) e o complexo tutelar emergente deste período surge como força de controle e vigilância tanto da infância classificada como em perigo quanto daquela considerada perigosa (LEMOS \& VASCO, 2012).

No século XX, a cultura da institucionalização passou a ser debatida por diferentes profissionais preocupados com o bem-estar das crianças. A mentalidade caritativa e assistencialista começou a tomar forma jurídica, com a criação, em 1927, do primeiro Código de Menores. Durante a vigência do Código, internaram-se, então, milhares de crianças classificadas como vadias, abandonadas, órfãs e delinquentes (VIANNA, 1999). 
As condições gerais dos Códigos (1927 e 1979) previam a resolução dos problemas dos "menores" por meio da internação. A missão de salvar as crianças de suas famílias começou a sobrecarregar o Estado e os sérios problemas da institucionalização evidenciaram-se, estimulando o surgimento de movimentos sociais e propiciando o surgimento de um novo paradigma.

É importante acentuar que a forma de subjetivação aqui chamada de "menorismo" é consoante com as concepções ideológicas de sua época. Porém, de muitas formas, ele naturaliza as desigualdades e fundamenta estruturas sociais importantes e precisa ser melhor compreendido, já que continua presente. $\mathrm{O}$ menorismo teria as seguintes características:

1) Ele é um mecanismo de dominação de classes, da burguesia ascendente sobre a classe trabalhadora mais empobrecida, em geral composta pelos filhos dos escravos e outras populações não brancas;

2) O racismo, portanto, é um de seus traços mais marcantes, já que tem como alvo de sua tutela e repressão principalmente as crianças negras e indígenas sobreviventes aos processos de colonização, escravidão e exploração;

3) É uma prática assistencialista, utilizando as instituições totais supostamente para proteger as crianças, dividindo-se aí na ambiguidade da assistência e proteção a eles e na defesa e proteção aos segmentos considerados importantes da sociedade;

4) $\mathrm{O}$ menorismo sustentou com suas práticas de assistência, educação e profissionalização a ideia de "preparar para o trabalho", de fazer com que as crianças conhecessem o valor do trabalho, quando na verdade preparava a conformidade às atividades laborais mais subalternas e visava o lucro da exploração desses "menores";

5) Tem caráter repressivo com todos os "menores" e mais forte contra os que esboçam qualquer questionamento sobre a autoridade; tais características apenas pioraram na revisão do Código de Menores da época da ditadura militar (1979). Para a criança pobre destinava-se o dispositivo do recolhimento e institucionalização e, para os "menores infratores", as torturas do internato; 
6) É seletivo, arbitrário e discriminador por natureza, ou seja, parte da divisão entre pobres merecedores e não merecedores, dignos e indignos, menores e crianças, famílias ideais e desestruturadas;

7) É patriarcal e machista, pois se apoia na ideia de pátrio poder, do pai homem, chefe de família e trabalhador exemplar, desqualificando a mulher que está à frente da família e também as famílias diversas, compostas por mulheres ou por casais homoafetivos;

8) Localiza como necessariamente problemática - e por vezes como nociva - a "família de origem", via de regra pobre, sem acesso à educação formal e de cultura diferente da "família ideal";

9) É tutelar, em um sentido do excesso de controle, pois intervém diretamente na família de origem e determina o destino da criança a partir do olhar para esta, permitindo ou não o seu retorno após a separação e institucionalização;

10) É moralista, pois submete crianças e famílias à moralidade conservadora, em geral baseada no ideário cristão e em concepções ideais burguesas sobre mulher, família e educação, não acolhendo as diferenças.

Em 1990, durante o processo de redemocratização, o Estatuto da Criança e do Adolescente foi promulgado, revogando o Código de Menores, afirmando o paradigma da proteção integral. Essa doutrina baseou-se na Declaração Universal dos Direitos Humanos, de 1948, na Constituição Federal de 1988, na Convenção Internacional dos Direitos da Criança, de 1989 e em outras normativas (CUNHA, 2018). Foi reflexo também de forte atuação em prol da infância, onde graves denúncias de maus tratos tornaram-se intoleráveis.

Na perspectiva protetiva, o Estatuto alterou as possibilidades no trato com este público, outorgando-lhes direitos necessários ao seu pleno desenvolvimento, corroborando a importância da responsabilização da família e do Estado pela proteção e assistência. De acordo com o artigo 227 da Constituição Federal de 1988, a criança passou de objeto a sujeito de direitos. Além de gozar de assistência em diversos níveis, deveria estar, preferencialmente, em família (BRASIL, 1990). 
Com o Estatuto, a institucionalização encontrou limites. Contudo, sua promulgação não garantiu a real efetivação da proteção integral porque a materialização da lei, em contextos onde predomina a crença menorista, tem resistido ao enfoque garantista. É preciso assinalar a persistência das demais representações, que podem ganhar mais força em momentos de retrocesso em relação aos direitos humanos.

\section{Permanências da visão menorista e seus efeitos}

A Análise Institucional, em seu campo transdisciplinar, por meio de seus conceitos sobre os mecanismos que movimentam as instituições, possibilita o questionamento de diferentes forças instituídas dirigidas aos que são alvo das políticas públicas. Aponta também para a possibilidade de um novo olhar sobre a instituição família, um lugar instituinte, em constante transformação. Nessa linha de pensamento, o novo paradigma de inclusão e proteção proposto pelo Estatuto também contribui para o repensar da criança, especialmente em momento de afirmação de direitos.

O campo em questão apresenta-se em conflito com o que determina a legislação, caminhando vagarosamente rumo à concretização da proteção integral. Devido em parte à mentalidade menorista, a internação ainda tem sido excessiva e indevidamente utilizada, considerando-se que: 1) há dispositivos legais e teóricos para a concretização da medida de acolhimento em famílias acolhedoras; 2) essa medida tem sido reconhecida como melhor opção para alguns casos em detrimento da institucionalização; 3) o reordenamento propõe mudanças de posturas e práticas assistencialistas e 4) as famílias pobres ainda são desqualificadas.

Diversos pensadores do desenvolvimento emocional da infância (WINNICOTT, 1998, 1999, 2000) respaldaram a necessidade dos cuidados e continuidade dos mesmos, principalmente nos primeiros anos de vida. Esses estudiosos certamente influenciaram o desenvolvimento da proposta de acolhimento familiar. A instituição já foi reconhecida como problemática para o desenvolvimento infantil (MORÉ \& SPERANCETTA, 2010) e o acolhimento familiar está contemplado em nossa legislação, menos oneroso que a institucionalização. Entretanto, a lógica asilar permanece em muitos municípios. 
É verdade que alguns entraves emperram sua implementação e escolha como possibilidade mais adequada para certas situações de violações de direitos: seu recente reconhecimento legal; o desconhecimento da possibilidade de aplicar essa política pública por parte de numerosos membros do SGD; o número insuficiente de famílias dispostas a acolher; o caráter voluntário e não remunerado do serviço (BAPTISTA \& ZAMORA, 2016); a pouca capacitação específica dos técnicos e das próprias famílias acolhedoras; a escassa sistematização de dados sobre o atendimento e sua efetividade, entre outros. Entretanto, grande parte dessa problemática é, possivelmente, contornada por meio de investimento financeiro e social, se houver o real desejo de promover novas formas mais humanizadas de gestão da infância vulnerável.

As famílias dessas crianças no entorno do acolhimento têm sido olhadas e tratadas como pouco capazes de cuidar de sua prole. Repetidas vezes olhadas como "fora da norma", ainda têm perdido suas crianças. Contudo, cabe questionar: o que as torna incapazes? Ainda a pobreza?

Reverbera na prática a desqualificação das famílias pobres, o público alvo mais direto das políticas públicas. A inserção na categoria "negligente" pode afastá-las dos filhos (MARTINS, 2006; CORREIA, 2015). Há de se refletir sobre o dado de realidade dos casos de "alta complexidade"; as situações específicas precisam ser problematizadas pelo sistema de garantias de direitos.

A negligência tem formas diferentes e carece de contextualização cultural para que se possa, realmente, identificá-las como tal. As famílias têm potencialidades e precisam ser referenciadas. Seus desejos e saberes precisam ser ouvidos e a elas cabe o apoio necessário nos momentos de crise.

Em diferentes partes do mundo, crianças querem suas famílias, precisam se sentir pertencentes a algum lugar, necessitam de contornos seguros para suas vidas. Menos importa a pobreza se o afeto lhes sejam proporcionadas continuamente. Se não as referenciamos em suas histórias, elas acabam escondendo aquele tempo da memória e duvidando da sua identidade. 


\section{CONSIDERAÇÕES FINAIS}

A partir do paradigma da proteção integral e corroborada pela necessidade de reordenamento institucional, situa-se o acolhimento familiar enquanto medida provisória que intenta proteger e reintegrar a criança ao seu ambiente de pertencimento. Este movimento pode acontecer por meio do empreendimento de esforços para o fortalecimento e apoio à família de origem, ou sua extensão, no intuito de manter os elos de vida da criança.

Contudo, com base na reflexão desenvolvida no presente artigo, foi possível problematizar a persistência da lógica asilar, apesar das inúmeras constatações sobre sua inadequação e a racionalidade "menorista" como coadjuvante de muitas práticas dirigidas à infância na atualidade.

Castro (2016), a partir da leitura de Foucault, reflete sobre a excessiva necessidade de regulação baseada em um exercício de saber-poder, onde certas famílias estão mais sujeitas à judicialização, a um olhar patologizante sobre seus comportamentos, desqualificando-as enquanto potenciais cuidadoras (LEMOS \& VASCO, 2012; NASCIMENTO, 2002). Não se trata de negar que algumas famílias pobres ameacem seus filhos. Trata-se de problematizar, em primeiro lugar, a dificuldade do cumprimento da lei, estabelecendo a política e, em segundo, privilegiando os casos possíveis de colocação em famílias, principalmente crianças muito pequenas.

Olhar para a família pobre como potencialmente capaz de cuidar de seus filhos e com o suporte protetivo que lhe pertence é um pensamento ainda em construção e cercado de reticências. O movimento, do início da República, de retirar a criança de sua família com um viés higienista, deixou marcas muito presentes.

Questiona-se o que realmente está em jogo neste novo modelo de reordenamento; quais as razões do pouco investimento na reintegração familiar; quais as novas alianças de poder por trás do discurso maquiado de bondade, caridade e dever religioso; quais dispositivos de controle das famílias ainda permanecerão caso um novo olhar não seja possível. 
Contudo, parece existir a possibilidade de superação do "menorismo" se os atores sociais envolvidos puderem refletir sobre seu olhar na direção da desconstrução de certos preconceitos. Cabe a todos os operadores do Sistema de Garantia de Direitos conhecer a história, repensar e reformular suas práticas no atendimento na direção de fazer valer os direitos adquiridos.

É preciso também apostar na participação popular, inclusive das crianças e adolescentes, como um princípio vivo das decisões a serem tomadas, em qualquer momento. Uma nova lógica de proteção integral dificilmente será estabelecida com base em antigas práticas. Nesse sentido cabe finalmente perguntar: a quem o acesso a direitos humanos tanto incomoda?

\section{REFERÊNCIAS}

ALTOÉ, S. (Org.) René Lourau. Analista institucional em tempo integral. São Paulo: Hucitec, 2004.

ARANTES, E. Direitos da criança e do adolescente: um debate necessário. Rio de Janeiro, Psicologia Clínica, Rio de Janeiro, v. 24, n. 1, p. 45-56, s/d, 2012.

. Duas décadas e meia de vigência da Convenção sobre os Direitos da Criança: algumas considerações. 1.ed. In: BRANDÃO, E. P. (Org.) Atualidades em Psicologia Jurídica. Rio de Janeiro: Nau, 2016, p. 53-96.

ASSIS, S. G.; FARIAS, L. O. P. (Orgs.) Levantamento nacional das crianças e adolescentes em serviço de acolhimento. São Paulo: Hucitec, 2013.

BAPTISTA, M. V. Algumas reflexões sobre o Sistema de Garantia de Direitos. Serviço Social e Sociedade, São Paulo, n. 109, p. 179-199, jan./mar., 2012. Disponível em: s http://dx.doi.org/10.1590/S0101-66282012000100010> Acesso em: setembro de 2018.

BAPTISTA, R. F. Acolhimento familiar, experiência brasileira: reflexões com foco no Rio de Janeiro. Dissertação (Mestrado em Serviço Social) - Faculdade de Serviço Social, Pontifícia Universidade Católica do Rio de Janeiro, Rio de Janeiro, 2006.

; ZAMORA, M. H. É possível profissionalizar as famílias acolhedoras no Brasil? Polêmica, Rio de Janeiro, v. 16, n. 2, p. 14-28, abr./jun., 2016. Disponível em: < https://www.epublicacoes.uerj.br/index.php/polemica/article/view/22906.> Acesso em: janeiro de 2019.

BAREMBLITT, G. F. Compêndio de análise institucional e outras correntes: teoria e prática. 5. ed., Belo Horizonte, MG: Instituto Felix Guattari, 2002. 
BOWLBY, J. Uma base segura: Aplicações clínicas da teoria do apego. Porto Alegre: Artes Médicas, 1989.

Apego e perda: separação - angustia e raiva. São Paulo: Martins Fontes, 1998.

BRASIL. Decreto $\mathrm{n}^{\circ}$ 17.943-A de 12 de outubro de 1927. Consolida as leis de assistencia e protecção a menores. Revogado pela Lei $\mathrm{n}^{\circ}$ 6.697. Disponível em <http://www.planalto.gov.br/ccivil 03/decreto/1910-1929/D17943A.htm> Acesso em: março de 2019.

. Lei $\mathrm{n}^{\circ}$ 6.697, de 10 de outubro de 1979. Institui o Código de Menores. Revogada pela Lei n ${ }^{\circ}$ 8.069, de 1990. Disponível em <http://www.planalto.gov.br/ccivil_03/LEIS/19701979/L6697.htm> Acesso em: março de 2019.

. Constituição da República Federativa do Brasil de 1988. Brasil; Casa Civil. Disponível em: 〈http://www.planalto.gov.br/ccivil_03/constituicao/constituicao.htm> Acesso em: março de 2019.

. Lei no 8069, de 13 de julho de 1990. Estatuto da Criança e do Adolescente. Disponível em: 〈http://www.planalto.gov.br/ccivil_03/leis/L8069.htm> Acesso em: outubro de 2018.

. Lei n ${ }^{\circ}$ 8.742, de 7 de dezembro de 1993. Dispõe sobre a organização da Assistência

Social e dá outras providências. Disponível em
<http://www.planalto.gov.br/ccivil 03/leis/L8742.htm> Acesso em: março de 2019.

. Lei $\mathrm{n}^{\circ}$ 12.010, de 3 de Agosto de 2009. Dispõe sobre adoção; altera as Leis $\mathrm{n}^{\text {os }} 8.069$, de 13 de julho de 1990 - Estatuto da Criança e do Adolescente, 8.560, de 29 de dezembro de 1992; revoga dispositivos da Lei $\mathrm{n}^{\circ} 10.406$, de 10 de janeiro de 2002 - Código Civil, e da Consolidação das Leis do Trabalho - CLT, aprovada pelo Decreto-Lei $n^{\circ} 5.452$, de $1^{\circ}$ de maio de 1943; e dá outras providências; Presidência da República. Casa Civil. Subchefia para Assuntos Jurídicos.

BRONFENBRENNER, U. A ecologia do desenvolvimento humano. Porto Alegre: Artes Médicas, 1996.

BULCÃO, Irene. A produção de infâncias desiguais: uma viagem na gênese dos conceitos "criança" e "menor". In: NASCIMENTO, M. L. (Org.) Pivetes: a produção de infâncias desiguais. Niterói: Intertexto. Rio de Janeiro: Oficina do Autor, 2002, p. 61-73.

CAMURI, A. C. et al. Direitos sexuais no sistema socioeducativo do Rio de Janeiro. Mnemosine, Rio de Janeiro, v. 8, n. 1, p. 43-71, s/d, 2012.

CANTALICE, L. B. O. A produção do conhecimento em torno dos Conselhos Tutelares: uma análise de teses e dissertações. In: SOUZA FILHO, R.; SANTOS, B. R.; DURIGUETTO, M. L. (Orgs.) Conselhos tutelares: desafios teóricos e práticos da garantia de direitos da criança e do adolescente. Juiz de Fora: Ed. UFJF, 2011, p. 39-56.

CASTRO, E. Introdução à Foucault. 1.ed. Belo Horizonte: Autêntica Editora, 2015. 
Vocabulário de Foucault- um percurso pelos seus temas, conceitos e autores. 2.ed. Belo Horizonte: Autêntica Editora, 2016.

CONSELHO MUNICIPAL DOS DIREITOS DA CRIANÇA E DO ADOLESCENTE [CMDCA]. Política de Abrigo. CMDCA/RJ. Deliberação nº 032/96. Rio de Janeiro, 2003.

CONSELHO NACIONAL DE ASSISTÊNCIA SOCIAL [CNAS]; CONSELHO NACIONAL DOS DIREITOS DA CRIANÇA E DO ADOLESCENTE [CONANDA]. Orientações Técnicas: Serviços de Acolhimento para Crianças e Adolescentes. 2.ed. Brasília: CONANDA \& CNAS, 2009.

CONSELHO NACIONAL DE DIREITOS DA CRIANÇA E DO ADOLESCENTE [CONANDA]. Resolução ${ }^{\circ} 113$, de 19 de abril, 2006. Brasília, 2006. Disponível em: < http://www.mprs.mp.br/infancia/legislacao/id2410.htm> Acesso em: maio de 2018.

CONSELHO NACIONAL DE ASSISTÊNCIA SOCIAL [CNAS]. Resolução CNAS nº 109 , de 11 de novembro de 2009: Tipificação Nacional dos Serviços Socioassistenciais. Brasília: CNAS, 2009.

CONSELHO NACIONAL DE ASSISTÊNCIA SOCIAL [CNAS]. Resolução CNAS nº 23, de 27 de setembro de 2013. Aprovação dos critérios de elegibilidade e partilha dos recursos para expansão qualificada e reordenamento dos Serviços de Acolhimento para crianças, adolescentes e jovens no âmbito dos estados e municípios. Brasília: CNAS, 2013.

CORREIA, P. C.; ZAMORA, M. H.; BICALHO, P. P. Em nome da proteção: crianças, adolescentes e seus direitos violados. Polis e Psique, Porto Alegre, v. 8, n. 3, p. 180-209, s/d, 2018. Disponível em <https://doi.org/10.22456/2238-152X.78822> Acesso em: março de 2019.

CORREIA, V. L. C. Negligência, acolhimento institucional e direito à convivência familiar e comunitária de crianças e adolescentes. Dissertação (Mestrado em Serviço Social) - Faculdade de Serviço Social, Pontifícia Universidade Católica do Rio de Janeiro, Rio de Janeiro, 2015.

COSTA, J. F. Ordem médica e norma familiar. Editora Graal, 1979.

CUNHA, J. R. A Garantia de Direitos Humanos de Crianças e Adolescentes: Uma Perspectiva Normativa e Filosófica Brasileira. Revista Jurídica Luso-Brasileira, Lisboa, Portugal, n. 6, p. 2207-2243, $\quad$ s/d, $2018 . \quad$ Disponível em <http://www.cidp.pt/revistas/rjlb/2018/6/2018_06_2207_2243.pdf $>$. Acesso em: março de 2019.

DARAHEM, G. C., SILVA, A. P. S.; COSTA, N. R. A. Da teoria do apego à Rede de Significações: Maria Clotilde Rossetti-Ferreira e a psicologia do desenvolvimento brasileira. Temas em Psicologia, Ribeirão Preto, v. 17, n. 1, p. 191-207, s/d, 2009.

DELGADO, P. O. Acolhimento Familiar em Portugal. Conceitos, práticas e desafios. Psicologia \& Sociedade, Florianópolis, v. 22, n. 2, p. 336-344, mai./ago., 2010a. Disponível em: 〈http://www.scielo.br/pdf/psoc/v22n2/14.pdf> Acesso em: outubro de 2018. 
A reforma do acolhimento familiar de crianças: conteúdo, alcance e fins do novo regime jurídico. Análise Social, Lisboa, Portugal, v. 45, n. 196, p. 555-580, s/d, 2010b.

DELGADO, P.; CARVALHO, J.; PINTO, V. S. Crescer em família: a permanência no acolhimento familiar. Revista Interuniversitária, Sociedad Iberoamericana de Pedagogia Social, Sevilla, España, n. 23, p. 123-150, s/d, 2014. Disponível em: 〈http://www.redalyc.org/pdf/1350/135029519007.pdf > Acesso em: dezembro de 2018.

et. al. Acolhimento Familiar em Portugal e Espanha: Uma Investigação Comparada sobre a Satisfação dos Acolhedores. Psicologia: Reflexão e Critica, Porto Alegre, v. 28, n. 4, p. 840-849, s/d, 2015. Disponível em: < http://www.scielo.br/pdf/prc/v28n4/0102-7972-prc-2804-00840.pdf> Acesso em: dezembro de 2018.

DONZELOT, J. A polícia das famílias, 2. ed. Rio de Janeiro: Edições Graal, 1986.

FALEIROS, V. P. Infância e processo político no Brasil. In: PILOTTI, F.; RIZZINI, I. (Orgs.) A arte de governar crianças. A história das políticas sociais, da legislação e da assistência à infância no Brasil. Rio de janeiro: Instituto Interamericano Del Niño, Santa Úrsula, Amais Livraria e Editora, 1995, p. 47-98.

FOUCAULT, M. Vigiar e punir. Petrópolis: Vozes, 1987.

GOFFMAN, E. Manicômios, prisões e conventos, 8. ed. São Paulo: Perspectiva, 2008.

GONÇALVES, H. S. Infância e violência no Brasil. Rio de Janeiro: Nau, 2003.

HABIGZANG, L. F; KOLLER, S. H. Violência contra crianças e adolescentes. Teoria, pesquisa e prática. Porto Alegre: Artmed, 2012.

IANELLI, A. M., ASSIS, S. G.; PINTO, L. W. Reintegração familiar de crianças e adolescentes em acolhimento institucional em municípios brasileiros de diferentes portes populacionais. Ciência \& Saúde Coletiva, Rio de Janeiro, v. 1, n. 20, p. 39-48, jan., 2015. Disponível em: 〈http://www.scielo.br/pdf/csc/v20n1/pt_1413-8123-csc-20-01-00039.pdf > Acesso em: junho de 2018.

KOLLER, S. H. Ecologia do desenvolvimento humano: pesquisa e intervenção no Brasil. São Paulo: Casa do Psicólogo, 2011.

LEMOS, F. C. S. O Estatuto da Criança e do Adolescente no Brasil atual. Revista Psicologia Política, São Paulo, v. 8, n. 15, p. 93-106, jun., 2008. Disponível em: <http://pepsic.bvsalud.org/scielo.php?script=sci arttext\&pid=S1519-549X2008000100007> Acesso em: outubro de 2018.

Inquietações a respeito das práticas de conselheiros tutelares: proteção e controle. In: SANTOS, B. R.; FILHO, R. S.; DURIGUETTO, M. L. (Org.) Conselhos Tutelares: desafios teóricos e práticos da garantia de direitos da criança e do adolescente. 1.ed. Juiz de Fora: UFJF, v. 1, 2011, p. 75-85. 
.; VASCO, D. S. Alguns percursos históricos entre o higienismo e a medicalização na atenção à infância e às famílias. Artifícios. Revista do Difere, Belém, v. 2, n. 4, p. 1-20, s/d, 2012. Disponível em: 〈http://www.artificios.ufpa.br/Artigos/D\%20Flavia.pdf > Acesso em: dezembro de 2018.

LUNA, M. (Coord.) Informe Latinoamericano. Situación de la niñez sin cuidado parental o en riesgo de perderlo en América latina. Contextos, causas y respuestas. Ciudad Autónoma de Buenos Aires, Argentina, 2010.

MARTINS, F. F. S. Crianças negligenciadas: a face (in) visível da violência familiar. Dissertação (Mestrado em Psicologia) - Faculdade de Psicologia, Pontifícia Universidade Católica de Minas Gerais, Belo Horizonte, 2006.

MINISTÉRIO DO DESENVOLVIMENTO SOCIAL E COMBATE À FOME [MDS]. Conselho Nacional de Assistência Social. Política Nacional de Assistência Social. Brasília: MDS/CNAS, 2004.

Censo SUAS 2012. Secretaria de Avaliação e Gestão da Informação; Secretaria Nacional de Assistência Social, 2013.

Censo SUAS 2014: CRAS, CREAS, Centros POP, Gestão Municipal, Gestão Estadual, Conselho Municipal, Conselho Estadual, e Unidades de Acolhimento. Brasília, DF: MDS, Secretaria de Avaliação e Gestão da Informação; Secretaria Nacional de Assistência Social, 2015.

MIRANDA, P.; ZAMORA, M. H. Direitos fundamentais de crianças e adolescentes em favelas cariocas: problematizando a produção de negligência. Polêmica, Rio de Janeiro, v. 8, n. 1, p. 33-48, jan./mar., 2009.

MODULO CRIANÇA E ADOLESCENTE [MCA]. $17^{\circ}$ censo da população infantojuvenil acolhida no estado do rio de janeiro, 2016. Disponível em: <http://mca.mp.rj.gov.br/wpcontent/uploads/2016/11/17censo_estadual.pdf > Acesso em: novembro 2018.

MORÉ, C. L. O.; SPERANCETTA, A. Práticas de pais sociais em instituições de acolhimento de crianças e adolescentes. Psicologia \& Sociedade, Florianópolis, v. 22, n. 3, p. 519-528, set./dez., 2010. Disponível em: 〈http://www.scielo.br/pdf/psoc/v22n3/v22n3a12 > Acesso em: novembro 2018.

NASCIMENTO, M. L.; CUNHA, F. L.; VICENTE, L. M. D. Desqualificação da família pobre como prática de criminalização da pobreza. Revista Psicologia Política. São Paulo, v. 7, n. 14, s/d, 2007.2 Disponível em: 〈http://www.fafich.ufmg.br/ psicopol/seer/ojs/viewarticle.php?id=48\&layout=html\&locale > Acesso em: novembro 2018.

NASCIMENTO, M. L., LACAZ, A. S.; ALVARENGA FILHO, J. R. Entre efeitos e produções: ECA, abrigos e subjetividades. Barbaroi, Santa Cruz do Sul, v. 33, p. 50-64, ago./dez., 2010. Disponível em: 〈https://online.unisc.br/seer/index.php/barbaroi/article/viewFile/1521/1315> Acesso em: maio de 2018. 
(Org.) Pivetes: engrenagens de infâncias desiguais. Rio de Janeiro: Intertexto e Oficina do Autor, 2002.

Abrigo, pobreza e negligência: percursos de judicialização. Psicologia \& Sociedade, Belo Horizonte, v.24, p.39-44, no.spe, 2012. Disponível em: <http://www.scielo.br/pdf/psoc/v24nspe/07.pdf > Acesso em: novembro 2018.

OLIVEIRA, R. C. S. Quero voltar para casa: o trabalho em rede e a garantia do direito à convivência familiar e comunitária para crianças e adolescentes que vivem em abrigo. São Paulo: $\quad$ AASPTJ, 2007.2 Disponível em: $<$ http://www.tjsp.jus.br/download/corregedoria/pdf/infanciajuventude/agentevoltapracasa. pdf $>$ Acesso em: maio de 2018.

PAPALIA, D. E.; SALLY, W. O.; FELDMAN, R. D. Desenvolvimento Humano. São Paulo: Artmed, 2013.

RAGO, M. Do Cabaré ao lar. A utopia da cidade disciplinar. Brasil, 1890-1930. Rio de Janeiro: Paz e Terra, 1985.

RIBEIRO, P. R. M. A criança brasileira nas primeiras décadas do século XX: a ação da higiene mental na psiquiatria, na psicologia e na educação. In: BOARINI, M.L. (Org.) Higiene e raça como projetos: higienismo e eugenismo no Brasil. Maringá: EDUEM, 2003, p. 71-96.

RIZZINI, I.; RIZZINI, I. A institucionalização de crianças no Brasil: percurso histórico e desafios do presente. Rio de Janeiro: Editora PUC-Rio, 2004.

; PILOTTI, F. A Arte de Governar crianças: a história das políticas sociais, da legislação e da assistência à infância no Brasil. 2. ed. São Paulo: Cortez, 2009.

RODRIGUES, H. B. C. À beira da brecha: uma história da Análise Institucional francesa nos anos 60. In: AMARANTE, P. (Org.) Ensaios: subjetividade, saúde mental, sociedade. Rio de Janeiro: Fiocruz, 2000, p. 195-256.

Análise institucional francesa e transformação social: o tempo (e contratempo) das intervenções. In: ALTOÉ, S.; RODRIGUES, H. B. C. (Orgs.) Análise Institucional - Saúde Loucura 8. São Paulo: Hucitec, 2004, p. 115-163.

Sejamos realistas, tentemos o impossível. Desencaminhando a psicologia através da Análise Institucional In: JACÓ-VILELA, A. M.; FERREIRA, A. A. L.; PORTUGAL, F. T. (Orgs.) História da Psicologia: rumos e percursos. Rio de Janeiro: Nau, 2005, p. 525-594.

RODRIGUES, M. M. Aventuras no Mundo da Higiene - Ecos do discurso médico no texto de Erico Verissimo. Cadernos de História da Educação, Uberlândia, v. 9, n. 2, p. 439-454, jul./dez., 2010.

ROSSETTI-FERREIRA, M. C. et. al. Acolhimento de crianças e adolescentes em situações de abandono, violência e rupturas. Psicologia: Reflexão e Crítica. Porto Alegre, v. 25, n. 2, p. 390- 
399, s/d, 2012. Disponível em: 〈http://dx.doi.org/10.1590/S0102-79722012000200021> Acesso em: dezembro de 2018.

SILVA, T. R.; LEHFELD, N. A. S. O SUAS em movimento: desafios postos ao reordenamento da rede de serviços de acolhimento institucional para crianças, adolescentes e jovens. I seminário Internacional de pesquisa em políticas públicas e desenvolvimento social. Franca, 2014. Disponível em: $<$ http://www.franca.unesp.br/Home/Posgraduacao/planejamentoeanalisedepoliticaspublicas/is ippedes/thiago-rodrigo-da-silva.pdf> Acesso em: dezembro de 2018.

SILVA, F. L. Como ocorreu a reintegração familiar? Investigando este processo em uma amostra de crianças acolhidas. Dissertação (Mestrado em Psicologia) - Faculdade de Psicologia. Universidade de São Paulo, Ribeirão Preto, 2012.

WINNICOTT, D. W. Os bebês e suas mães. São Paulo: Martins Fontes, 1998. Privação e delinquência. São Paulo: Martins Fontes, 1999.

Psicoses e cuidados maternos. In: WINNICOTT, D. W. Da Pediatria à Psicanálise. Rio de Janeiro: Imago, 2000, p. 305-315.

VIANNA, A. R. B. O mal que se adivinha: polícia e menoridade no Rio de Janeiro, 1910-1920. Rio de Janeiro: Arquivo Nacional, 1999.

ZAMORA, M. H.; PEREIRA, I. Adolescentes em conflito com a lei e suas famílias. In: JULIÃO, E. F. Juventudes, políticas públicas e medidas socioeducativas. Rio de Janeiro: DEGASE, 2013, p. 147-162.

Data de Submissão: 06/05/2019

Data de Aceite: 18/10/2019 